\title{
André Gide, “EEdipe" suivi des brouillons et textes inédits
}

\section{Gian Luigi Di Bernardini}

\section{(2) OpenEdition}

1 Journals

\section{Édition électronique}

URL : http://journals.openedition.org/studifrancesi/9331

DOI : 10.4000/studifrancesi.9331

ISSN : 2421-5856

Éditeur

Rosenberg \& Sellier

\section{Édition imprimée}

Date de publication : 1 juin 2008

Pagination : 222

ISSN : 0039-2944

\section{Référence électronique}

Gian Luigi Di Bernardini, « André Gide, "Frdipe" suivi des brouillons et textes inédits », Studi Francesi [En ligne], 154 (LII | I) | 2008, mis en ligne le 30 novembre 2015, consulté le 09 janvier 2021. URL : http:// journals.openedition.org/studifrancesi/9331 ; DOI : https://doi.org/10.4000/studifrancesi.9331

Ce document a été généré automatiquement le 9 janvier 2021.

\section{(c) $(1) \&$}

Studi Francesi è distribuita con Licenza Creative Commons Attribuzione - Non commerciale - Non opere derivate 4.0 Internazionale. 


\title{
André Gide, “EDdipe” suivi des brouillons et textes inédits
}

\author{
Gian Luigi Di Bernardini
}

\section{RÉFÉRENCE}

ANDRÉ GIDE, "CEdipe" suivi des brouillons et textes inédits, édition critique établie, présentée et annotée par Clara DEBARD, Paris, Honoré Champion, 2007, pp. 324.

Clara Debard offre aux spécialistes la première édition critique de l'œdipe d'André Gide, l'un de ses ouvrages les moins connus. Dans son ample «Introduction» (pp. 11-136), Debard affronte d'abord le problème des sources du drame et rappelle que Gide ne considère pas sa pièce comme une réécriture de Sophocle. D'ailleurs, le foisonnement d'allusions à la culture contemporaine (à la psychanalyse, par exemple) et les autocitations de l'œuvre gidienne resémantisent radicalement la pièce, désormais simple prétexte pour un débat d'idées portant sur le rapport de l'homme à Dieu. Ensuite, Debard se penche sur les thèmes (la satire familiale, la question sociale, la religion) et sur les aspects structuraux du texte: la déconstruction de la temporalité mythique, le rôle du chœur, le rapport d'Ædipe avec Thésée et avec le reste de l'œuvre gidienne. Debard n'oublie pas la réception de l'ouvrage non plus, d'abord chez les intimes (la réaction négative de Martin du Gard, par exemple), puis chez les professionnels, parmi lesquels on compte les premiers metteurs en scène, Pitoëff et Hartung, dans les années Trente.

2 Debard explique, en faisant recours au Journal et aux correspondances de Gide, la genèse particulièrement longue et fragmentaire de la pièce. Faute d'évidents points de repère (le changement de graphie excepté) et les brouillons étant perdus en grande partie, Debard ne peut pas reconstruire de manière ponctuelle les différentes couches de l'écriture et opter pour une approche génétique. Debard reproduit donc l'édition courante parue dans la «N.R.F.» en 1931 (et dernière à avoir été revue par l'auteur) en 
pleine page, avec l'orthographe corrigée; en note, elle place les variantes et, en italique, des commentaires explicatifs.

3 Après les brouillons et des textes inédits, trouve sa place un «Dossier» (pp. 265-306) constitué par de multiples matériaux: la liste des représentations d'Ædipe jusqu'à 1978, les consignes de mise en scène de Jean Vilar pour l'acte II, la liste des comptes rendus des représentations, des extraits de ces mêmes comptes rendus, des lettres inédites relatives à EEdipe. Une «Bibliographie sélective» (pp. 307-314) et un «Index» (pp. 315-321) des noms terminent le volume. 